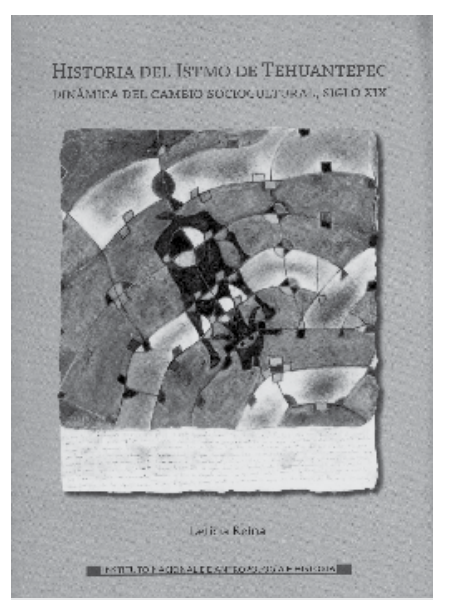

- Historia del Istmo de Tehuantepec.

Dinámica del cambio sociocultural,

siglo $x I X$

Leticia Reina, 2013

Instituto Nacional de Antropología

e Historia, México, 366 pp.
The Isthmus, Women and Identities. Society, Economy and Culture of Tehuantepec in the $\mathrm{XIX}^{\text {th }}$ Century

Ricardo PÉrez MontFort Centro de Investigaciones y Estudios Superiores en Antropología Social-Distrito Federal,

Distrito Federal, México ripemont5408@gmail.com

Desacatos 50, enero-abril 2016, pp. 202-212

\section{Del istmo, sus mujeres \\ y sus identidades. Sociedad, economía y cultura de
Tehuantepec en el siglo XIX economía y cultura de
Tehuantepec en el siglo XIX}

\author{
RICARDO PÉREZ MONTFORT
}


lo anecdótico, sino porque es un compendio inaudito de referencias antiguas y contemporáneas sobre el papel del Istmo de Tehuantepec en la historia moderna de México, llamada así por Daniel Cosío Villegas. Según una noción que recuerda un tanto la microhistoria de Luis González, aunque renovada con gran tino, este libro es una especie de "historia universal" del Istmo de Tehuantepec durante el siglo XIX. Se trata de una historia de ese tipo, que recupera el sentido antiguo de lo "universal", esto es, como adjetivo que "se aplica al sujeto que es científico, y noticioso en muchas y varias maneras", como diría un diccionario del siglo XVIII (Diccionario de autoridades, 1990: 392).

Como buen libro científico, sin hacer mucho caso al orden temático expuesto en las primeras líneas, su corpus general se divide en cuatro capítulos que siguen los lineamientos clásicos de los estudios históricos cuyo objeto es una porción específica del país que se evidencia en el título de la obra: el territorio y sus pobladores, la economía regional, la sociedad y la política, y la identidad y la cultura. En el primer apartado, además de recorrer los antecedentes prehispánicos y coloniales de la región, queda claro que el istmo es una compleja zona semitropical formada por varias microrregiones que se han disputado hegemonías y poblamientos. Entre herederos novohispanos, haciendas y proyectos de dominio cuyas responsabilidades redundan de manera paulatina en compañías y propietarios extranjeros, los pueblos originarios zapotecas, huaves, mixes y zoques trataron de resistir por vías legales las pretensiones foráneas y al hacerlo llenaron archiveros y notarías. Aun cuando esto implicó un enorme trabajo quemapestañas para historiadores como Leticia Reina, es sorprendente que las conclusiones de esa labor sean tan contundentes, como expone la autora al final de este capítulo: "hubo un gran cambio en la tenencia de la tierra, se crearon problemas legales y conflictos, pero no hubo cambios generalizados en el uso de suelo". Remata con una frase clara que sin duda rompe los esquemas, en referencia puntual al territorio istmeño: “Así durante el porfiriato, hacia finales del siglo XIX, fueron pocos los lugares y muy focalizados en donde hubo cambios en la estructura agraria” (p. 128).

En el segundo capítulo, Leticia Reina desbroza con fino análisis los dilemas de la producción y el consumo locales, desde los primeros años independientes hasta la formación de grandes haciendas ganaderas y maiceras, y la explotación de líneas de comercio internacionales. Como era de esperarse, dedica un amplio subcapítulo al asunto de la construcción de la vía interoceánica con toda su cauda de broncas ingenieriles, comerciales y migratorias. Pocos proyectos de comunicación impactaron tanto a una región en el mundo decimonónico como el ferrocarril transístmico en aquella cinturita de la república mexicana. A partir de entonces, pocas cosas quedaron sin transformarse en Tehuantepec. Es probable que uno de los cambios más impactantes haya sido el que sufrió la sociedad que habitaba en aquellos parajes, que resulta ser el tema del siguiente apartado.

El tercer capítulo versa, pues, sobre los habitantes de aquel istmo. Entre 1861 y 1910, por ejemplo, la ciudad de Tehuantepec casi duplicó su población, mientras que Juchitán la triplicó. Esto resulta por demás interesante si se piensa que aquella comunidad contaba sobre todo con una población de indígenas zapotecos de $85 \%$, frente a $8 \%$ de mestizos y 6.8\% de blancos (p. 219). Aquí salen a colación aspectos centrales de la dinámica poblacional del istmo, entre los que destacan tanto el peso de sus mujeres como transmisoras de cultura regional, como el proceso de "zapotequización" de la mayoría de los extranjeros, pero sobre todo el espíritu de lucha y de identidad política que a favor de la defensa del territorio muestran sus pobladores ante los afanes separatistas y los conflictos entre caciques locales, líderes nacionales e imperios.

El capítulo cuarto, hay que reconocerlo, es el que resulta tal vez el más heterodoxo de este libro. 


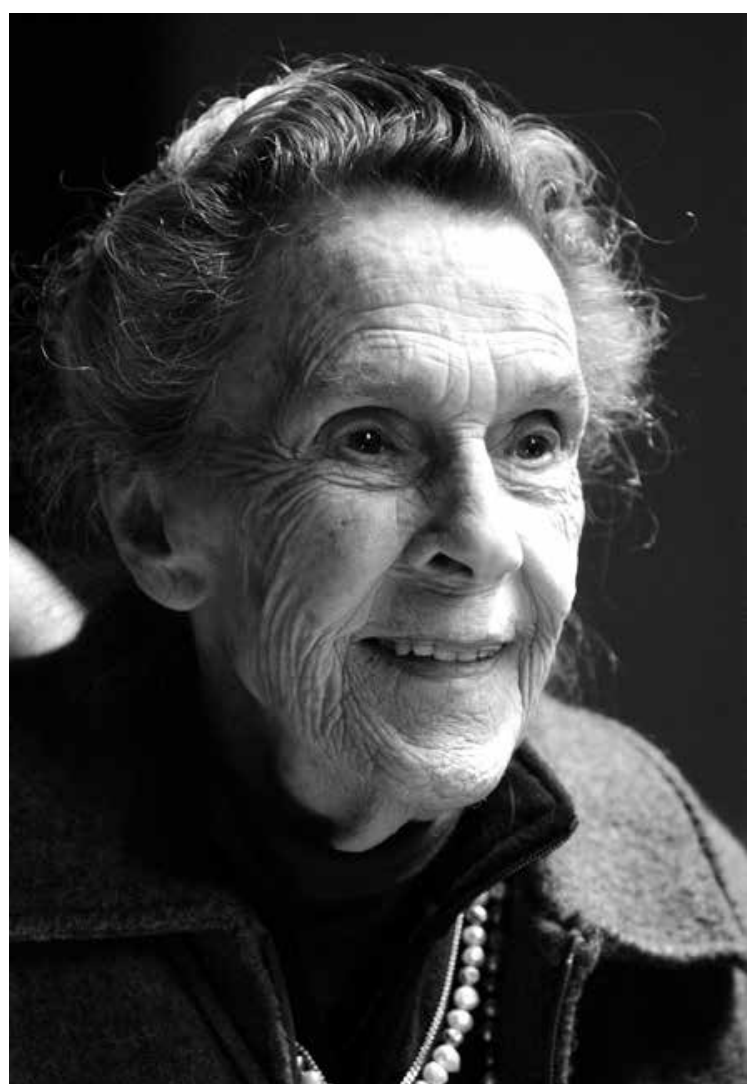

RICARDo RAmíreZ ARRIOLA/ARChIVO360.com • Leonora Carrington, pintora, escultora y escritora mexicana, durante su homenaje en el Museo José Luis Cuevas. Ciudad de México, 12 de febrero de 2009.

No sólo porque trata temas como la identidad y la cultura, sino porque la autora lo hace con particular discreción carente de prejuicios y afanes estereotípicos. Varios autores se han abocado al trabajo en torno de las tehuanas y el folclor istmeño desde hace más de un siglo y medio. Es muy conocida la facilidad con la que se cae en la glorificación de la patria chica o en las hipérboles de los escritores regionalistas, así como de algunos promotores de los lugares comunes del arte popular y las tradiciones mexicanas. Tocadas con sus famosos velos de encaje blanco y sus huipiles de seda finamente bordados y multicolores, se supone que las tehuanas representan a una mujer que en sus primeras apariciones en la literatura y el mundo del arte mexicanista derrochaba sensualidad y erotismo. Gracias a su temprana promoción realizada por artistas como Saturnino Herrán, Diego Rivera, Miguel Covarrubias y Frida Kahlo, al igual que escritores como José Vasconcelos y Andrés Henestrosa, las tehuanas se convirtieron en las primeras décadas del siglo XX en las habitantes de una "geografía imaginaria" que invitaba a que "ninguna apetencia de la carne quedara insatisfecha". El mismo Vasconcelos las describió así:

\begin{abstract}
De una casa de paja salen dos mujeres ondulando las caderas, tenso el corpiño por la erección de los pezones y erguida la cabeza que sostiene el gran cesto redondo de las mercaderías... Caminan sobre la arena dorada con pies limpios, ligeros y desnudos. En sus desnudas pantorrillas hay la consistencia de la palma real. Y en sus labios la frescura opalina del agua de coco tierno (citado en Sierra, 1992: 22).
\end{abstract}

Las tehuanas fueron entonces un estereotipo más que pobló el mundo de la cultura y la farándula mexicanas desde la década de 1920 hasta la de 1950 y se consolidó como supuesto representante genuino de la mujer mexicana. La sensualidad, los atuendos y los bailes de la tehuana fueron explotados por el teatro de revista y por el cine hasta transformarla en una mestiza con fuertes rasgos indígenas que promovía la añoranza de un paraíso tropical al parecer perdido (Covarrubias, 1946). Lejos de continuar con estas representaciones un tanto chabacanas y apuntaladas por la comercialización reciente de la Guelaguetza turística, Leticia Reina explora el origen y el desenvolvimiento del traje de las tehuanas en crónicas y grabados que se hunden hasta el siglo XVIII. En particular, menciona las fotografías del XIX y el XX, así como la música, el baile y las canciones que se han atribuido el adjetivo de ser "típicos" de las expresiones populares istmeñas. En su prosa aparecen tradiciones prehispánicas zapotecas, así como referencias inquisitoriales novohispanas, narraciones 
de viaje decimonónicas y pretendidos estudios del folclor regional, con el fin de llevar al lector no sólo a conocer el proceso en que se formaron estos referentes identitarios locales, sino a disfrutar del balanceo del vals tehuano, la estridencia de los piteros y tamboreros —o cajeros - muní, y el afán de la célebre pieza de La Sandunga, con aquella frase que la distingue y que dice "Ay, mamá, por Dios". Basta leer estas referencias para darse cuenta de que muchos estereotipos regionales se han construido a partir de veleidades y requiebros que tienen más que ver con lo anecdótico que con lo propiamente identitario.

Para rematar, la autora nos lleva de la mano por las páginas finales dedicadas a las fiestas titulares, las patronales y las famosas "velas", en las que los zapotecas del istmo, dice Reina, "recordaban y recuerdan quiénes son, de dónde vienen y cuáles son sus anhelos para el porvenir” (p. 313). Así concluye esta historia universal del Istmo de Tehuantepec, que habla de la conformación de su territorio, de los vaivenes de su economía, de la transformación de su sociedad y de los tesoros de su cultura "abierta a los cuatro vientos", vistos durante el cambiante siglo XIX. Es así como el lector contemporáneo puede disfrutar y sobre todo aprender de nuevas formas de acceder a la formación regional decimonónica del istmo tehuantepecano, leyendo y releyendo estas páginas que Leticia Reina ha bordado sobre una urdimbre que une magníficamente la historia con la antropología.

\section{Bibliografía}

Covarrubias, Miguel, 1946, Mexico South. The Isthmus of Tehuantepec, Alfred A. Knopf, Nueva York.

Diccionario de autoridades, 1990 [1737], facsimilar, Gredos, Madrid.

Sierra Torre, Aída, 1992, Geografías imaginarias, Instituto Mexiquense de Cultura, Toluca. 